Objective To determine the nature of cognitive function, frequency and severity of cognitive deficit, in 10 to 15-year-old extremely preterm (EPT) children born at 2 tertiary care centers in Sweden adhering to a policy of universal resuscitation of all infants born alive.

Methods The outcomes of 121 surviving EPT children, born 1992-1998, were compared to a control group of 100 term children. Children were assessed with WISC- III at 9-16 years of age. Relationship of perinatal risk factors (PNRF) with the outcomes was examined with multivariate regression analyses (MRA).

Results The EPT group had a mean IQ of 80 (controls 103). 29\% of the EPT children had an IQ below 70 (controls 3.4\%), of which $9 \%$ were under IQ 55 (controls 0 ). Another $30 \%$ of EPT children had IO within the mildly delayed range, 70-84 (controls 12.6\%). The preterm group has a greater variance between cognitive domains, with the language skills as relative strength and spatial thinking as pronounced weakness. MRA revealed that only gestaional age was inversely related to FSIO (B 7.1, P 022) and Performance IQ (B 9.8, $\mathrm{P}<001)$

Conclusion Cognitive dysfunctions remain high in EPT children. These numbers are similar to those from centres with less active perinatal care policies. Very few have severe cognitive impairment that curtail their activities in daily life.

\section{EXECUTIVE FUNCTIONS AT 10-15 YEARS IN CHILDREN BORN AT < 26 WEEKS' GESTATION AFTER ACTIVE PERINATAL CARE: UPPSALA-UMEÅ STUDY}

doi:10.1136/archdischild-2012-302724.1228

J Karlsson, B Hagglof, A Farooqi. Department of Clinical Sciences, Umea University, Umea, Sweden

Aim To determine the nature, frequency and severity of executive dysfunction (EDF) in 10 to 15 -year-old extremely preterm (EPT) children born at 2 tertiary care centers in Sweden adhering to a policy of universal resuscitation of all infants born alive.

Design/methods The outcomes of 121 surviving EPT (86\% of all EPT survivors) children born 1992 through 1998 were compared to a matched control of children born at term. Cognitive function was assessed by WISC-III. Executive functions were assessed by DKEFS Tower of London and ADHD-symptoms by Conners 10-item rating scale. Relationship of perinatal risk factors (PNRF) with the outcomes was examined with appropriate statistical analyses.

Results The EPT children exhibited significant EDF compared with their controls in many EFs such as impulsivity, inattention and planning ability even after controlling for intelligence (IQ). Mean scores in EPT and controls were, respectively, 79 vs 101 in full scale IO, $\mathrm{P}<0.001 ; 2.5$ vs $0.5, \mathrm{P}<0.001$ in Impulsivity; 9.1 vs $11.8, \mathrm{P}<0.001$ in planning ability; and 4.4 vs 1.62 in ADHD symptoms. Severe impairments were exhibited in only a small minority of EPT children. No statistical conclusions were altered when children with substantial neurosensory impairment were excluded. Relation of PNRF will also be discussed.

Conclusions School-aged children who were born EPT in the 1990s are at greater risk for developing EDF and these contribute excess morbidity over cognitive impairment in EPT children. Thus these children require ongoing neuropsychological review throughout their childhood and adolescence.

\section{COMPUTERIZED WORKING MEMORY TRAINING IS EFFECTIVE IN PRETERM BORN CHILDREN AT PRESCHOOL AGE}

doi:10.1136/archdischild-2012-302724.1229

1,2K Hermansen Grunewaldt, ${ }^{1,2} \mathrm{~J}$ Skranes, ${ }^{1,2} \mathrm{AM}$ Brubakk, ${ }^{1,3} \mathrm{GCC}$ Løhaugen. ${ }^{1} \mathrm{Dept}$ of Lab. Medicine, Children's and Women's Health, Norwegian University of Science and Technology; ${ }^{2}$ Dept of Pediatrics, St. Olav University Hospital, Trondheim; ${ }^{3}$ Dept of Pediatrics, Sørlandet Hospital, Arendal, Norway

Background and Aims Working memory (WM) is defined as the skill to retain and manipulate information "on-line" over short periods of time. Deficits in WM are frequently reported in preterm children and are associated with cognitive, behavioural and academic problems. We wanted to evaluate if a software-based computer program would improve WM, attention and behaviour in VLBW children at preschool age.

Methods This prospective study included 20 preterm children. Mean birth weight 1099g(SD 311), mean gestational age 29 weeks(SD 2.8). At age 5-6, the children trained with the Cogmed JM computer program for 10-15 minutes each day, 5 days a week for 5 weeks. The children were assessed before and 4 weeks after training. Effect on trained WM tasks were assessed by improvement measures included in the computer program. Non-trained WM and generalization effects were assessed by neuropsychological (NEPSY) tests. Parental questionnaires regarding ADHD symptoms were performed before and after completed training.

Results The children improved on trained WM tasks (Start-Index: mean 42.1; SD 6.3, Max-Index 60.6; SD 5.7. p $\leq 0.001$.). The group also improved on non-trained WM tasks and showed a generalization effect on auditory attention, phonological awareness and visual and verbal memory. A Stepped-Wedge-Design showed that improvements in test results after training were not due to test-retest effects. There was a trend towards significantly reduced ADHD scores after training.

Conclusion Computerized WM training in VLBW pre-schoolers have positive effects on trained and non-trained WM tasks as well as generalizing effect on verbal and visual learning and memory functions.

\section{THE PREDICTIVE VALUE OF EARLY AEEG PATTERNS FOR FUNCTIONAL OUTCOME AT SCHOOL AGE IN PRETERM INFANTS}

doi:10.1136/archdischild-2012-302724.1230

N Brandenbarg, A Roescher, K van Braeckel, $\mathrm{H}$ ter Horst, A Bos. Department of Pediatrics, Division of Neonatology, University of Groningen, University Medical Center Groningen, Groningen, The Netherlands

Introduction Brain activity of preterm infants can be assessed by amplitude integrated electroencephalography (aEEG).

Objective To determine whether early aEEGs of preterm infants are associated with functional outcome at 7 years.

Methods Eighteen infants participating in a prospective observational study in 2004 were seen for follow-up at median age of 7 years, 5 months. Median GA was 28.9wks (26.7-32.9). aEEGs of $2 \mathrm{~h}$ duration were recorded within $48 \mathrm{~h}$ and one and two weeks after birth. aEEGs were assessed by pattern recognition and by calculating the mean of aEEG amplitude centiles. Functional outcome was determined by assessing intelligence, attention, verbal memory, visuospatial processing, executive functioning and motor skills.

Results In case of burst suppression $<48 \mathrm{~h}$ Total IO was 13 points lower $(P=0.018)$, Performance IQ was 18 points lower $(P=0.016)$ and visuospatial processing scores were $0.68 \mathrm{SD}$ lower $(P=0.027)$. Mean p5 and p50 centiles recorded $<48 \mathrm{~h}$ after birth correlated positively with Total IQ $(r=0.507, r=0.495$, repectively; $P<0.05)$, Performance IQ $(r=0.578, r=0.514$, respectively; $P<0.05)$, selective attention ( $r=0.586, r=0.577$, respectively; $P<0.05$ ), visuospatial processing $(r=0.488, r=0.534$, respectively; $P<0.05)$ and fine motor skills $(r=0.558, r=0.556$, respectively; $P<0.05)$. All correlations remained significant at one week and after adjustment for GA, except for visuospatial processing and fine motor skills.

Conclusion Burst suppression and lower aEEG amplitude centiles within $48 \mathrm{hrs}$ and at one week after birth were associated with 
poorer cognition at 7 years. This indicates that early aEEGs may be useful in predicting functional outcome of preterm children at school age.

\section{NEURODEVELOPMENTAL OUTCOME AMONG MULTIPLES AND SINGLETONS: A REGIONAL NEONATAL INTENSIVE CARE UNIT'S EXPERIENCE IN TURKEY}

doi:10.1136/archdischild-2012-302724.1231

$1 Z$ Eras, ${ }^{2 B M}$ Özyurt, ${ }^{3} 0$ Erdeve, 'ED Sakrucu, ${ }^{2} S S$ Oguz, ${ }^{2} F E$ Canpolat, ${ }^{2} \mathrm{~N}$ Uras, ${ }^{4} \mathrm{U}$ Dilmen. ${ }^{1}$ Developmental Behavioral Pediatrics Unit; ${ }^{2}$ Neonatology, Zekai Tahir Burak Maternity and Teaching Hospital; ${ }^{3}$ Neonatology, Ankara University, Faculty of Medicine; ${ }^{4}$ Neonatology, Zekai Tahir Burak Maternity and Teaching Hospital, Yıldırım Beyazıt University Department of Pediatrics, Ankara, Turkey

Objective The aim of this study was to compare the neurodevelopmental outcome at 12-18 months' corrected age between multiples and singleton preterm infants.

Methods We designed a prospective study of preterm infants $(\leq 32$ weeks gestation) born and hospitalized in the neonatal intensive care unit between November 2008 and November 2009, whose assessments were performed at 12-18 months' corrected age. Neurodevelopmental impairment was defined as the presence of any one of the following: moderate or severe cerebral palsy, severe bilateral hearing loss or bilateral blindness, mental developmental index score or psychomotor developmental index score less than 70 . Results were compared for both multiples and singleton infants.

Results A hundred and fifty-nine multiples and 211 singleton infants were assessed at 12-18 months' corrected age. The neurodevelopmental outcome including all parameters at 12-18 months' corrected age in multiples was not significantly different from singleton preterm infants.

Conclusions Multiple gestation in preterm infants is not associated with an increased risk of neurodevelopmental impairment at 12-18 months' corrected age compared to singleton preterm infants. For further information long-term and high-participated neurodevelopmental follow-up and evaluation at pre-school age will be needed.

\section{DO ORAL PROBIOTICS AFFECT GROWTH AND NEURODEVELOPMENTAL OUTCOMES IN VERY LOW BIRTH WEIGHT PRETERM INFANTS?}

doi:10.1136/archdischild-2012-302724.1232

${ }^{1} \mathrm{FN}$ Sarı, ${ }^{2} \mathrm{Z}$ Eras, ${ }^{3} \mathrm{EA}$ Dizdar, ${ }^{4} 0$ Erdeve, ${ }^{3} \mathrm{SS}$ Oguz, ${ }^{3} \mathrm{~N}$ Uras, ${ }^{5} \mathrm{U}$ Dilmen. ${ }^{1}$ Noenatology; ${ }^{2}$ Developmental Behavioral Pediatrics Unit; ${ }^{3}$ Neonatology, Zekai Tahir Burak Maternity and Teaching Hospital; "Neonatology, Ankara University, Faculty of Medicine${ }^{5}$ Neonatology, Zekai Tahir Burak Maternity and Teaching Hospital/YIIdırım Beyazıt University Department of Pediatrics, Ankara, Turkey

Objective To evaluate the growth and neurodevelopmental outcomes of very low birth weight (VLBW) preterm infants supplemented with oral probiotics for the prevention of necrotising enterocolitis (NEC).

Study Design This prospective follow-up study was conducted in a cohort of VLBW preterm infants enrolled in a randomizedcontrolled clinical trial to evaluate the efficacy of oral probiotics for the prevention of NEC. Growth outcomes included weight, length and head circumference. Neurodevelopmental assessment was done using the Bayley Scales of Infant Development II (BSID-II). The primary outcome was neurodevelopmental impairment at 18-24 months' corrected age.

Results A total of 221 infants completed the trial protocol. Of the 208 infants eligible for follow-up, 174 infants (86 in the probiotics group and 88 in the control group) were evaluated. There were no significant difference in growth and neurodevelopmental outcomes between the two groups.
Conclusion Oral probiotic administrated to VLBW infants to reduce the incidence and severity of NEC started with the first feed did not affect growth and neurodevelopmental outcomes at 18-24 months' corrected age.

\section{THE IMPACT OF MEDICAL HOME MODEL ON NEURODEVELOPMENTAL OUTCOMES OF VERY PRETERM INFANTS}

doi:10.1136/archdischild-2012-302724.1233

'Z Eras, ${ }^{2} \mathrm{G}$ Kanmaz, ${ }^{2} \mathrm{BM}$ Ozyurt, ${ }^{2} \mathrm{FE}$ Canpolat, ${ }^{1} \mathrm{ED}$ Sakrucu, ${ }^{3} \mathrm{U}$ Dilmen. ${ }^{1}$ Developmental Behavioral Pediatrics Unit; ${ }^{2}$ Neonatology, Zekai Tahir Burak Maternity and Teaching Hospital; ${ }^{3}$ Neonatology, Zekai Tahir Burak Maternity and Teaching Hospital, Yıldırım Beyazit University Department of Pediatrics, Ankara, Turkey

Objective The aim of the study is to compare the 2-year neurodevelopmental outcome of very low birth weight and/or very preterm infants followed with "medical home model" implemented in a big maternity hospital in Turkey with the primary health care.

Methods We designed a prospective controlled study of infants born $\leq 32$ week's gestation and/or $\leq 1500 \mathrm{~g}$ and hospitalized. After discharge, intervention group were followed with in the concept of medical home model and control group were followed in the concept of primary standart health care. At 18-24 months' of corrected age, the neurological examinations and the developmental assessments using the Bayley Scales of Infant Development-II were performed.

Results The cerebral palsy rates in the intervention and control group were $10.6 \%(n=17)$ and $17.4 \%(n=27)$ respectively and the difference was not statistically significant $(p=0.107)$. Whereas the rate of neurodevelopmental impairment in the intervention group was significantly lower than the control group $(25 \%$ and $38,7 \%$; $\mathrm{p}=0.011$ ).

Conclusion We demonstrated that beginning a good follow-up process within the context of medical home model, efficient developmental support and performing guidance for early diagnose reduced the negative effects of VLBW and/or prematurity on neurodevelopmental impairment at 2 years of age.

\section{4 PREDICTORS OF LITERACY IN VERY PRETERM INFANTS: A LONGITUDINAL STUDY}

doi:10.1136/archdischild-2012-302724.1234

'A Guarini, 'A Sansavini, 'S Savini, ${ }^{2} \mathrm{R}$ Alessandroni, ${ }^{2} \mathrm{G}$ Faldella. 'Department of Psychology; ${ }^{2}$ Institute of Neonatology, University of Bologna, Bologna, Italy

Background and Aims As revealed by several studies, a very preterm birth may affect language, executive functions, verbal short term memory and literacy. The aim of this study was to investigate these competencies in very preterms compared to full terms, thus describing how language, executive functions and verbal short-term memory observed at the end of preschool age affect literacy at school age.

Methods Forty-two monolingual Italian very preterms (mean gestational age 29.7 weeks), with no history of major cerebral damage, were followed longitudinally at 6 years by investigating language (vocabulary, grammar, and phonological awareness), executive functions (syllabic and phonemic fluency) and verbal short-term memory (vowel span, non-word repetition) and again at 8 years on literacy (word and non-word reading and spelling). Two crosssectional groups of full term children were recruited as control groups ( 34 and 26 children at 6 and 8 years respectively).

Results Preterms showed lower abilities in language at 6 years and in literacy at 8 years, while no differences between groups regarding syllabic and phonemic fluency and short-term memory were found. Linear regression analyses revealed that in the preterm sample both language and verbal short-term memory had a predictive role on 